\title{
Spinosad combined with entomopathogenic nematode for biocontrol of the Mediterranean fruit fly (Ceratitis capitata [Wiedemann]) on citrus
}

\author{
Atef S. Abdel-Razek ${ }^{1}$ and Mahfouz M. M. Abd-Elgawad ${ }^{2 *}$ (1)
}

\begin{abstract}
Background: Cultivation of citrus (Sapindales: Rutaceae) crops is continuously expanding in Egypt given the favorable ingredients of citriculture. Notwithstanding the Egyptian rank as the world's largest orange exporter, the Mediterranean fruit fly (Medfly), Ceratitis capitata (Wiedemann) (Diptera: Tephritidae), is one of the major pests that considerably reduces the quality of citrus crops. Contrary to hazardous organophosphate insecticides that are commonly used to control the Medfly, biologically-based C. capitata control tactics were tried herein. The effect of spinosad as a bacterial fermentation product and the nematode Steinernema riobrave as biological insecticides applied singly or in combination on laboratory and field strains of Medfly were investigated.

Results: A significant difference in $\mathrm{LC}_{50}$ values was observed between laboratory strain (4.78 PPM) and field strain (8.12 PPM) of C. capitata larvae exposed to spinosad. A 1.7 fold decrease in susceptibility of field strain was recorded after treatment with spinosad. In a field experiment, a reduction in Medfly population by 80,37 , and $92 \%$ for spinosad, S. riobrave, and spinosad + nematode treatments was recorded, respectively.

Conclusions: Utilization of spinosad-S. riobrave combination in citrus fields, as a novel alternative for unhealthy chemical insecticides to control C. capitata in Egypt can be suggested. Use of this combination should be incorporated into a holistic management package that can be economically feasible and environmentally sustainable for Egyptian agriculture.
\end{abstract}

Keywords: Ceratitis capitata, Tracer 24, Steinernema riobrave, Insect management

\section{Background}

Citrus production suffers from the infestation by many insect pests of which the Mediterranean fruit fly (Medfly), Ceratitis capitata (Wiedemann) (Diptera: Tephritidae) ranks high. It is one of the most globally damaging pests of horticulture in the fruit fly group. Several specific control methods have been developed and applied successfully in many countries against C. capitata

\footnotetext{
*Correspondence: mahfouzian2000@yahoo.com

${ }^{2}$ Plant Pathology Department, National Research Centre, El-Behooth St., Dokki, Giza 12622, Egypt

Full list of author information is available at the end of the article
}

(Abd-Elgawad 2021). Common techniques are partial or cover-spraying of chemical insecticides with or without lures, hygiene, the Sterile Insect Technique (SIT), and the Bait Application Technique (BAT). They are recommended for control and suppression of $C$. capitata populations in fruit groves including citrus. Females of Tephritidae flies need certain amino acids as nutrition for developing their eggs and so they are attracted by the relevant baits. Buminal (5, 10 and $15 \%$ concentrations) was superior in attracting the Medfly (Amin 2003) as BAT is a widely used approach for general control of fruit flies. 
Development of chemical insecticides' resistance in pest and vector populations, the damage caused to non-target organisms, and the realization of other environmental hazards of these chemicals have led to an increasing interest in biological control measures (Trdan et al. 2020). Entomopathogenic nematodes (EPNs) are safe biocontrol agents that have been isolated and used successfully in the control of many insect pests in Egypt (Abd-Elgawad 2020) and elsewhere (Koppenhöfer et al. 2020). Moreover, chances that ease incorporating them into holistic management systems of various pests and pathogens should be seized. For example, using EPNs with certain chemical insecticides have proved to increase their effectiveness against pests (Koppenhöfer et al. 2020). Also, developing novel (compatible) techniques or leveraging synergies between EPNs and other pest management tactics to offer economically feasible application could be sought (Abd-Elgawad 2019). Thus, utilizing EPNs + spinosad, a bacterial fermentation product, is hypothesized in the present study to increase their biocontrol efficacy against $C$. capitata populations. As a natural substance, spinosad is toxic to fruit flies either by contact or following ingestion as it contains 2 chemicals: spinosyn A and spinosyn D (Ekesi et al. 2016).

This study examined the following points: (1) basic susceptibility of Medfly to spinosad, (2) susceptibility of Medfly to the EPN Steinernema riobrave, and (3) synergistic effects between spinosad and $S$. riobrave.

\section{Methods}

\section{Spinosad}

Spinosad was obtained from Dow-Agro-sciences as Tracer $24 \%{ }^{\circledR}$ formulation. Spinosad has already been organically certified (Racke 2007) and is being used against many insect pests, especially different fruit fly species (Abd-Elgawad 2021).

\section{The entomopathogenic nematode, Steinernema riobrave}

This highly pathogenic species is maintained in the microbial control laboratory, Giza, Egypt. It was originally isolated from the Rio Grande Valley of Texas, USA, and possesses several promising features (Grewal et al. 2005); its effective host range runs across multiple insect orders. It has ability to exploit aspects of both ambusher and cruiser means of finding hosts and tolerate soil temperatures at approx. $35{ }^{\circ} \mathrm{C}$ with persistence even under semi-arid conditions. Its small size provides high yields of EPN-infective juveniles (IJs) whether using in vivo or in vitro production methods.

\section{Laboratory tests}

Two different $C$. capitata strains were used, a laboratory strain (L) and a field strain (F), collected from Mashtoul
El-Souk Center, Sharkia Governorate, Egypt. The (L) strain was obtained from the standard laboratory culture, Egypt. Medfly was reared on a standard laboratory media; a formulated diet contained $4.83 \%$ Nutrifly, $15 \%$ corn cob fractions, $8 \%$ corn flour, $8.33 \%$ sugar, $0.23 \%$ sodium benzoate, $0.11 \%$ niacin, $0.13 \%$ citric acid, and $63.37 \%$ water (Hernandez et al. 2010) under constant conditions $\left(25 \pm 3{ }^{\circ} \mathrm{C}\right.$ and $70-80 \% \mathrm{RH}$ with a $16: 8$ (light: dark) cycle. Bioassay of the biological activity of the spinosad (Tracer $24 \%{ }^{\circledR}$ ) was determined, using treated media bioassay. The first instar larvae of $C$. capitata were used for both $C$. capitata strains. Spinosad doses used in both bioassays were 0 (only water), 2, 4, 8, 16, 32, 64, 125, 250, 500 and 1000 part per million (ppm). All sterile 9 -cm-diam. Petriplates of treated diet with spinosad were first air-dried for $1 / 2 \mathrm{~h}$. Control plates were prepared by diets treated with only distilled water. Afterwards, 5 first instar C. capitata larvae of each strain were separately placed in single plates and allowed to feed on the treated media for $24 \mathrm{~h}$. Percentages of mortalities were measured after $24 \mathrm{~h}$. The experiment was repeated 3 times in a completely randomized design.

\section{Field experiment}

Three rows each contains 12 'Succari' orange trees of 15 years old were divided into 4 blocks (3 trees each) in an organic farm at Mashtoul El-Souk Center, Sharkia governorate, Egypt. Treatments' blocks were separated by a minimum buffer area of $25 \mathrm{~m}$. Treatments were carried out in a randomized complete block design via applying the following 4 treatments just before sunset in January 2020: (1) Spinosad as cover spray treatment at the rate of $110 \mathrm{ppm}$ in $5 \mathrm{l}$ water tree ${ }^{-1}$, (2) $S$. riobrave as cover spray at the rate of $3 \times 10^{6} \mathrm{IJs}$ in $5 \mathrm{I}$ water tree ${ }^{-1}$. The spray (EPN suspension) is assumed to fall either on the fruits to protect them from depositing eggs by the insect females and kill the hatched larvae or drain into the ground beneath the tree canopy to kill the emerging insect adults, (3) S. riobrave-IJs + spinosad in $5 \mathrm{l}$ water tree ${ }^{-1}$, and (4) untreated control group (sprayed with water only). Treatments were applied as a foliar and fruit spray, using a back-back sprayer system with a nozzle attached to spray the whole tree. Three plastic International Yellow Pheromone traps with Concept's Medfly Biolure ${ }^{\circledR}$ (ammonium acetate, putrescine, trimethylamine) were placed in the middle of each replicate for the 4 treatments, $5 \mathrm{~m}$ between adjacent trees and $35 \mathrm{~m}$ between adjacent blocks to attract male flies in addition to the predominant female via attractive integrated pest management (IPM) trap with Biolure ${ }^{\circledR}$ as food bait (Ekesi et al. 2016). Traps were placed just after treatment applications, checked and removed 7 
d after application. Data were collected based on the number of the Medfly trapped.

\section{Statistical analysis}

Data were analyzed using probit analysis models in the Stat program (Finney 1964; Brown et al. 2001). Mortality rates were corrected by using the Abbott formula (Abbott, 1925). The significant differences between spinosad concentrations expected to kill $50 \%$ of C. capitata larvae or median lethal concentration $\left(\mathrm{LC}_{50}\right)$ values based on overlap of $95 \%$ confidence intervals were recorded. Data were analyzed using one-way analysis of variance (ANOVA) and followed by the least significant difference (LSD) test as a comparison of the mortality means. Dose-response chart of the dosage were plotted, using percentage mortality rates in Microsoft Excel spreadsheets. A randomized complete block design consisting of 4 treatments, with 3 replicates, each with 3 trees was used. Their field data were analyzed via two-way ANOVA and means separated using Tukey's $(P=0.05)$.

Table 1 Percent mortality of two Ceratitis capitata strains by spinosad doses

\begin{tabular}{llll}
\hline $\begin{array}{l}\text { Concentrations } \\
\text { No }\end{array}$ & $\begin{array}{l}\text { Concentrations } \\
\text { ppm }\end{array}$ & $\begin{array}{l}\text { Percent corrected } \\
\text { mortalities }\end{array}$ \\
\cline { 3 - 4 } & & $\begin{array}{l}\text { Laboratory } \\
\text { strain }\end{array}$ & Field strain \\
\hline 1 & 2 & 0 & 0 \\
2 & 4 & $18 \mathrm{a}$ & $10 \mathrm{a}$ \\
3 & 8 & $35 \mathrm{a}$ & $20 \mathrm{a}$ \\
4 & 16 & $40 \mathrm{a}$ & $22 \mathrm{~b}$ \\
5 & 32 & $42 \mathrm{a}$ & $30 \mathrm{~b}$ \\
6 & 64 & $60 \mathrm{a}$ & $42 \mathrm{~b}$ \\
7 & 125 & $70 \mathrm{a}$ & $62 \mathrm{~b}$ \\
8 & 250 & $100 \mathrm{a}$ & $70 \mathrm{~b}$ \\
9 & 500 & $100 \mathrm{a}$ & $100 \mathrm{a}$ \\
10 & 1000 & $100 \mathrm{a}$ & $100 \mathrm{a}$ \\
\hline
\end{tabular}

*Mortalities in the same raw followed by different letters are significantly $(P \leq 0.05)$ different from each other according to Tukey's test

\section{Results}

\section{Laboratory bioassays}

The C. capitata larvae displayed a concentrationdependent response to spinosad. A $100 \%$ mortality of the C. capitata field strain was detected after using 250 and 500 ppm but all doses induced mortality of the Laboratory strain $(P<0.05)$. An average of approximately 125 ppm of spinosad caused 70 and $62 \%$ mortality of laboratory and field strains, respectively (Table 1 ). According to $\mathrm{LC}_{50}$ values (Table 2), a significant difference was observed between laboratory strain $(4.78 \mathrm{ppm})$ and field strain $(8.12 \mathrm{ppm}), 24 \mathrm{~h}$. after treatment. Therefore, the laboratory strain was more susceptible to spinosad than the field one (Table 2). Obtained results suggested that even common confidence profiles set in this test would not overlap based on the $95 \%$ confidence interval (CI). The former strain demonstrated 4.96-4.59 CI at 95\% probability level (slope $=2.85 \pm 0.001$ ) compared to 9.25 $6.99 \mathrm{CI}$ at $95 \%$ probability level (slope $=8.09 \pm 0.39$ ) for the latter strain whose susceptibility decreased to 1.7 fold.

\section{Field experiment}

There was a significant $(P \leq 0.05)$ difference between the control and any of the 3 other treatments for the captured Medfly (Table 3). Means of the captured Medfly adults showed that the least number was recorded at the combined treatment of spinosad and nematode followed by spinosad alone, and then nematode alone in an ascending order. The highest numbers of the captured Medfly were recorded in the untreated check.

Table 3 Means of captured Medfly by traps baited in different treatments at 'Succari' orange grove

\begin{tabular}{lc}
\hline Treatments & $\begin{array}{l}\text { Mean No. of } \\
\text { Medfly adults/ } \\
\text { Trap* }\end{array}$ \\
\hline Spinosad & $25.7 \pm 6.80^{\mathrm{a}}$ \\
Steinernema riobrave & $45.6 \pm 3.10^{\mathrm{b}}$ \\
Spinosad + S. riobrave & $10.12 \pm 5.45^{\mathrm{c}}$ \\
Control & $125.00 \pm 62.75^{\mathrm{d}}$ \\
\hline
\end{tabular}

* Means followed by different letter are significantly $(P \leq 0.05)$ different from each other according to Tukey's test

Table 2 Probit analysis for two Ceratitis capitata strains treated with different concentrations of spinosad

\begin{tabular}{|c|c|c|c|c|c|c|}
\hline Strain & Slope \pm Standard Error & $\mathrm{LC}_{50}$ as ppm $(95 \% \mathrm{Cl})^{\mathrm{a}}$ & $\mathrm{LC}_{90}$ as ppm $(95 \% \mathrm{Cl})$ & Variance & Chi-square & $\mathrm{RR}^{\mathrm{b}}$ \\
\hline Laboratory & $2.853 \pm 0.001$ & $4.78(4.96-4.59)$ & $5.30(9.45-3.35)$ & 0.000072 & 0.00098 & - \\
\hline Field & $8.09 \pm 0.39$ & $8.12(9.25-6.99)$ & $11.69(19.8-3.25)$ & 0.00095 & 0.00 & 1.7 \\
\hline
\end{tabular}

${ }^{a}$ Confidence interval at $95 \%$ probability level; b: Resistance Ratio 
These results showed a reduction in Medfly populations by 80,37 and $92 \%$, for spinosad, nematode, and spinosad + nematode treatments, respectively, compared to the control treatments.

\section{Discussion}

In the laboratory study, the $\mathrm{LC}_{50}$ values concerning $C$. capitata $1^{\text {st }}$ instar larvae after $24-\mathrm{h}$ exposure to the biological compound, containing concentrate formulation of spinosad, was quite different between the 2 insect strains. Based on these $\mathrm{LC}_{50}$ values of spinosad, the field strain was less susceptible than the laboratory strain possibly due to drop in fitness of this latter as a common phenomenon in laboratory-reared organisms based on excessive culturing (Yu et al. 2010). As the laboratory strain has been in culture quite longer than the field strain, it is conceivable that some of the higher mortality recorded in the laboratory strain is due to trait deterioration in the laboratory strain. This goes in parallel to spinosad $\mathrm{LC}_{50}$ of C. capitata in Tunisia where $22 \mathrm{ppm}$ and $127.95 \mathrm{ppm}$ for laboratory and field population, respectively, were recorded (Guerfali et al. 2020). Reasonably, the field strain may simply have innate fitness factors.

Nevertheless, since the field strain was approximately 1.7 fold more insensitive to spinosad than the laboratory strain, the difference might also be due to the differential susceptibility of strains and intensive insecticide selection pressure in that area of collection. Notwithstanding the above-mentioned innate fitness in field populations of insect pests, a variety of biotic and abiotic factors can contribute to the apparent difference and fitness of field population relative to laboratory one ( $\mathrm{Yu}$ et al. 2010). Moreover, Stark et al. (2004) found that spinosad was remarkably similar in toxicity to all 3 economically important fruit fly (Diptera: Tephritidae) species: C. capitata, the melon fly Bactrocera cucurbitae (Coquillett), and the oriental fruit fly B. dorsalis (Hendel).

Obtained data proved that spinosad had not only significant effectiveness in the control of $C$. capitata but also its combination with $S$. riobrave could improve the EPN efficacy as biocontrol agent. Therefore, in order to minimize the negative effects of the chemicals on the environment and natural enemies in the management of pests, the natural insecticide spinosad could also be rotated with other pesticides or in low rates simultaneous with different insecticidal categories to avoid development of insect resistance in such programs. On the other hand, the present experiment showed a strong efficacy of the spinosad (i.e. $100 \%$ mortality) on C. capitata when applied at high rates, resulting in complete control in the laboratory bioassays. However, it is expected that the resistance to the spinosad might be developed if it is applied exclusively, i.e., without other biocontrol agent such as entomopathogenic nematodes. Moreover, field spraying of 'Succari' orange trees with a combination of spinosad-nematode material compared to either spinosad alone or S. riobrave alone and control provided acceptable control of the pest in commercial citrus cultivations. Likewise, comparable results of spinosad have been observed for wild Medflies in an eradication plan in Guatemala and Mexico (Rendon et al. 2000). Such plans should be fully exploited especially in the new citruscultivated areas as a recently published study (Dritsoulas et al. 2021) confirmed that reclaimed desert habitats of Egyptian citrus favor entomopathogenic nematode and microarthropod abundance. On the contrary, an exclusive use of spinosad may possibly generate the insect resistance (Guerfali et al. 2020). This might be indirectly shown herein by the higher resistance in field strain than laboratory strain as well. Therefore, spinosad may be used with a precaution that its long-term use can be contingent.

\section{Conclusions}

Obtained results indicated that spinosad $+S$. riobrave together may be used as an effective alternative tool for control of the Medfly in Egypt. As a novel alternative for synthetic chemical insecticides to control C. capitata in Egypt, this tactic should be applied on a wider scale to be incorporated into an integrated pest management programs to achieve economically feasible and environmentally sustainable agricultural systems. Additional studies are warranted to determine the economic feasibility of utilizing the combination used herein to control the Medfly.

\section{Abbreviations}

SIT: Sterile Insect Technique; BAT: Bait Application Technique; EPNs: Entomopathogenic nematodes; IJs: Infective juveniles; IPM: Integrated pest management; ANOVA: Analysis of variance; Cl: Confidence interval; $L_{50}$ : Median lethal concentration; LSD: Least significant difference; PPM: Part per million.

\section{Acknowledgements \\ This research was supported by In-House project No. 10120609 entitled: "Insect pests control for some of exporting vegetable and fruit crops pro- duced organically." The authors thank NRC administrative departments for their help in the financial support. The authors acknowledge the support in part of this study by the US-Egypt Project cycle 17 (no. 172) entitled "Preparing and evaluating IPM tactics for increasing strawberry and citrus production." This article is derived from the Subject Data funded in part by NAS and USAID, and that any opinions, findings, conclusions, or recommendations expressed in it are those of the authors alone, and do not necessarily reflect the views of USAID or NAS. The facilities offered by The National Research Centre are appreciated.}

\section{Authors' contributions}

All authors participated in the development and implementation of the reviewing plan and subsequently written it. The first author AA discussed the different parts of the article with MA and finalized the manuscript. All authors have read and approved the final manuscript. 


\section{Funding}

Financial support was partially made by both US-Egypt Project related to Science and Technology Development Fund via Project cycle 17 (no. 172) and National Research Centre, Egypt (In-house project No. 12050105) to develop and analyze the data.

\section{Availability of data and materials}

The datasets used and/or analyzed during the current study are available from the corresponding author on reasonable request.

\section{Declarations}

\section{Ethics approval and consent to participate}

Not applicable.

\section{Consent for publication}

Not applicable.

\section{Competing interests}

The authors declare that they have no competing interests.

\section{Author details}

'Pests and Plant Protection Department, National Research Centre, Dokki, Giza 12622, Egypt. ${ }^{2}$ Plant Pathology Department, National Research Centre, El-Behooth St., Dokki, Giza 12622, Egypt.

Received: 23 April 2021 Accepted: 11 August 2021

Published online: 17 August 2021

\section{References}

Abbott WS (1925) A method of computing the effectiveness of an insecticide. J Econ Entomol 18:265-267

Abd-Elgawad MMM (2019) Towards optimization of entomopathogenic nematodes for more service in the biological control of insect pests. Egypt J Biol Pest Cont 29:77. https://doi.org/10.1186/s41938-019-0181-1

Abd-Elgawad MMM (2020) Can rational sampling maximise isolation and fix distribution measure of entomopathogenic nematodes? Nematology 22(8):907-916. https://doi.org/10.1163/15685411-00003350

Abd-Elgawad MMM (2021) The Mediterranean Fruit Fly (Diptera: Tephritidae), a Key Pest of Citrus in Egypt. J Integ Pest Manag 12(1): 28. https://doi.org/ 10.1093/jipm/pmab025

Amin AA (2003) Studies on the peach fruit fly, Bactrocera zonata (Saund.) and its control in Fayoum Governorate. M.Sc. Thesis, Fac. Agric., Fayoum University.
Brown LD, Cai TT, DasGupta A (2001) Interval estimation for a binomial proportion. Stat Sci 16(2):101-133

Dritsoulas A, El-Borai FE, Shehata IE, Hammam MM, El-Ashry RM, Mohamed MM, Abd-Elgawad MMM, Duncan LW (2021) Reclaimed desert habitats favor entomopathogenic nematode and microarthropod abundance compared to ancient farmlands in the Nile Basin. J Nematol 53:1-13. https://doi.org/10.21307/jofnem-2021-047

Ekesi S, Mohamed SA, DeMeyer M (2016) Fruit fly research and development in Africa-towards a sustainable management strategy to improve horticulture. Springer Int Publ, Switzerland, pp 275-292. doi https://doi.org/10. 1007/978-3-319-43226-7_22

Finney DJ (1964) Probit analysis. Cambridge University Press, London

Grewal PS, Ehlers R-U, Shapiro-Ilan DI (2005) Nematodes as biocontrol agents. CABI Publishing, Wallingford

Guerfali MM, Hamden H, FadhI S, Djobbi W, Sillini L, Marzouki W, Ammar M (2020) Susceptibility of Ceratitis capitata Field and Laboratory strains to malathion and spinosad in Tunisia. Pak J Zool 52(4):1407-1414. https:// doi.org/10.17582/journal.pjz/20190102150141

Hernandez E, Escobar A, Bravo B, Montoya P (2010) Chilled packing systems for fruit flies (Diptera: Tephritidae) in the sterile insect technique. Neotrop Entomol 39:601-607

Koppenhöfer AM, Shapiro-Ilan DI, Hiltpold I (2020) Entomopathogenic nematodes in sustainable food production. Front Sustain Food Syst 4:125 https://doi.org/10.3389/fsufs.2020.00125

Racke KD (2007) A reduced risk insecticide for organic agriculture. Oxford University Press, Washington, pp 92-108

Rendon PO, Morales J, Rizzo J (2000) Applications of spinosad fruit fly bait in Guatemala. In: Proceedings of the fifth annual exotic fruit fly symposium, 10-12 September 2000, Riverside, California, USA

Stark JD, Vargas RI, Miller N (2004) Toxicity of spinosad in protein bait to 3 economically important tephritid fruit fly species (Diptera: Tephritidae) and their parasitoids (Hymenoptera: Braconidae). J Econ Entomol 97:911-915

Trdan S, Laznik Ž, Bohinc T (2020) Thirty years of research and professional work in the field of biological control (predators, parasitoids, entomopathogenic and parasitic nematodes) in Slovenia: a review. Appl Sci 10(21):7468. https://doi.org/10.3390/app10217468

Yu H, Gouge D, Shapiro-Ilan DH (2010) A Novel strain of Steinernema riobrave (Rhabditida: Steinernematidae) possesses superior virulence to subterranean termites (Isoptera: Rhinotermitidae). J Nematol 42(2):91-95

\section{Publisher's Note}

Springer Nature remains neutral with regard to jurisdictional claims in published maps and institutional affiliations.

\section{Submit your manuscript to a SpringerOpen ${ }^{\circ}$ journal and benefit from:}

- Convenient online submission

- Rigorous peer review

- Open access: articles freely available online

- High visibility within the field

- Retaining the copyright to your article

Submit your next manuscript at $\boldsymbol{\nabla}$ springeropen.com 